\title{
Some Recent Progress in Substorm Studies*
}

\author{
Wolfgang BAUMJOHANN \\ Max-Planck-Institut für Physik und Astrophysik, Institut für extraterrestrische Physik, \\ 8046 Garching b. München, Fed. Rep. of Germany
}

(Received December 17, 1985; Revised February 14, 1986)

\begin{abstract}
After reciting the present definition of a substorm as incorporating both the driven and the loading/ unloading process, this review will be addressed to two topics where major advances were made during the last two years: the downtail loss of substorm energy via plasmoid release and observational and theoretical studies of the substorm onset triggering mechanism. It will be concluded by pointing out the need of further studies, both observational and theoretical, of the substorm recovery phase and the poleward leap phenomenon.
\end{abstract}

\section{Introduction}

This review is based on a Reporter Talk presented at the Fifth IAGA Scientific Assembly and therefore has two constraints. Firstly, it has to be concise. Accordingly, it is restricted to a few major issues and cannot give justice to all work done in the field of substorm studies. Secondly, it is restricted to work done during the last two years (summer 1983 to summer 1985) and can thus not be exhaustive in the chosen topics.

The author will, however, try to point out major progress made and major questions left open during the last two years and hopes that this review together with a rather comprehensive one by BAKER et al. (1984a), which describes the full wealth of substorm phenomena and their understanding as of 1983, will serve as a guideline of the present understanding of the magnetospheric substorm.

\section{Substorm $=$ Driven Process + Loading/ Unloading Process}

The term magnetospheric substorm comprises all phenomena by which the earth's magnetosphere tries to adjust itself to enhanced solar wind input (during periods of southward IMF $B_{z}$ ). Nowadays widespread agreement exists (BAKER et al., 1984a; ROSTOKER et al., 1985) that this is done by two basic concurrent processes, the driven process and the loading/unloading process.

As displayed in the schematic (Fig. 1) some part of the enhanced solar wind energy input is directly dissipated by means of global convection leading to Joule heating of the auroral ionospheres by the enhanced convection currents and

*Based on a Reporter Review presented at the Fifth IAGA Scientific Assembly, Prague, August 1985. 


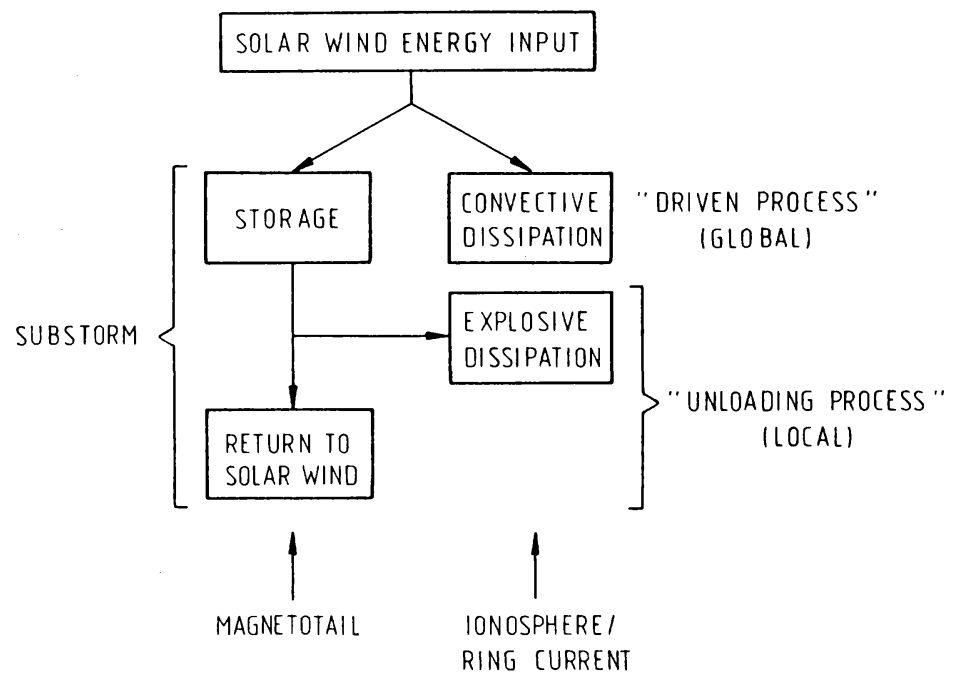

Fig. 1. Schematic summarizing the storage and dissipation of solar wind energy by both driven and loading/unloading process during a magnetospheric substorm (adapted from BAKER et al., 1984a).

deposition of particle energy in the auroral ionospheres as well as in the ring current. This energy dissipation is directly correlated with the solar wind energy input and constitutes a driven process, i.e. directly driven by the solar wind (see, for example, AKASOFU, 1983).

The remainder of the enhanced energy input is, at the same time, stored intermediately in the earth's magnetotail and then, at substorm onset (see Section 4), rather explosively released via Joule and particle heating of localized regions of the auroral ionospheres, injection of particles in the ring current, and return to the solar wind by the downtail release of plasmoids (see Section 3 ). This second substorm process, which operates concurrently to the driven process, has been named loading/unloading process.

Figure 2 gives both a schematic and some data on the concurrent operation of the driven and the loading/ unloading process during and after a period of enhanced solar wind input (BAKER et al., 1985a). Soon after the energy coupling between solar wind and magnetosphere is enhanced due to a southward IMF $B_{z}$, energy is stored in the magnetotail. Concurrently, with a time delay of about 10-20 min (due to the inductance of the system), energy is directly dissipated in the auroral ionosphere in the form of Joule heat. The stored energy is then (typically after about 30-60 min) explosively released during the so-called expansion phase, often but not necessarily after reduction of the solar wind energy input.

It should, however, be pointed out that in contrast to the impression one can get from the schematic in Fig. 2, direct dissipation and explosive dissipation of energy 

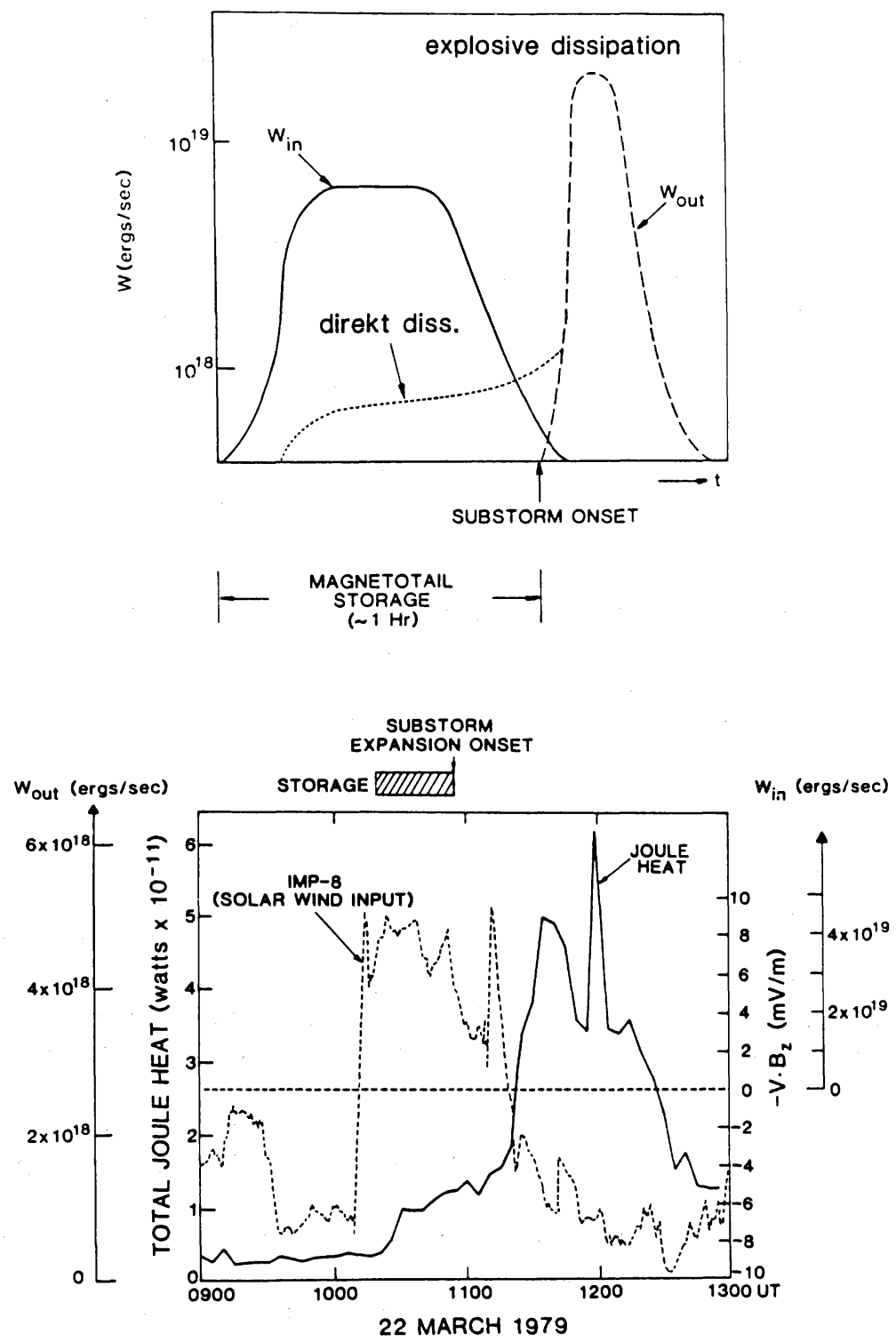

Fig. 2. Schematic (upper diagram) and data (lower diagram; solar wind energy input and ionospheric Joule heating) describing the direct dissipation (driven process) and the concurrent magnetotail storage and explosive dissipation (loading/unloading process) during a magnetospheric substorm (adapted from BAKER et al., 1985a). 
may coexist during the expansion phase with the direct dissipation being decreased or enhanced as compared to that during the storage (or growth) phase. This is apparent from the data presented by CLAUER and KAMIDE (1985) and KAMIDE and BAUMJOHANN (1985) when distinguishing between the convectional DP2 current system (eastward and westward electrojet centered around dawn and dusk), which is a signature of the driven process, and the DP1 substorm current wedge (centered around midnight), which is characteristic for the explosive dissipation of energy during the expansive phase (see also BAUMJOHANN, 1983).

Finally, it should be noted that the question if the driven process or the unloading process is the dominant one, i.e. dissipates more energy during a substorm, cannot be answered easily. In the case shown in Fig. 2 explosive dissipation is clearly dominant, but in a case presented by PELLINEN et al. (1982) the dominant energy dissipation must be attributed to the driven process. Hence, the relative importance of both processes varies from substorm to substorm. Statistical studies (prediction filtering) show that for moderate activity about $30 \%$ of the $A L$ index variation is due to the driven process while during strong activity more than half must be attributed to it (BARGATZE et al., 1985). Since the present $A L$ index is not perfect (see KAMIDE and AKASOFU, 1983; and BAUMJOHANN, 1986) and especially underestimates the real auroral electrojet for low and moderate activity, the above percentages may not be the final numbers, but the BARGATZE et al. (1985) study and the case studies mentioned above indicate that both processes are important for substorms.

\section{Unloading of Magnetotail Energy by Plasmoids}

Results from the ISEE-3 deep-tail mission have increased the present understanding of magnetotail physics considerably during the last two years, since a couple of phenomena which also effect the near-earth tail (but are much harder to detect here) are rather prominent in the deep-tail data. One phenomenon, and the most important for substorm physics, was the existence of tailward travelling closed magnetic structures, i.e. plasmoids, independently detected by HONES et al. (1984a) and SCHOLER et al. (1984a).

As sketched in Fig. 3, these plasmoids are created at substorm onset through the formation of a near-earth neutral line. Due to the sling-shot effect these plasmoids, with a typical length of about 70-80 $\mathrm{R}_{\mathrm{E}}$ (e.g., SCHOLER et al., 1984b), are then ejected downtail with a velocity of the order of $600 \mathrm{~km} / \mathrm{s}$ and engulf ISEE-3 at about $220 \mathrm{R}_{\mathrm{E}}$ down-tail some $30 \mathrm{~min}$ after substorm onset.

Evidence for the closedness of the magnetic structure comes from the observed $B_{z}$ polarity change from northward to southward during the traversal of the plasmoid and the detection of isotropic, i.e. trapped, hot electrons inside it (HONES et al., 1984; SCHOLER et al., 1984a). Further evidence was given by the observation of so-called tailward travelling (magnetic) compression regions, i.e. increased magnetic pressure and north-then-south tilting of the field (SLAVIN et al., 1984), which should be observed during the passage of a plasmoid if ISEE-3 is located further north or south than indicated in Fig. 3. Note, however, that the actual internal structure of a 


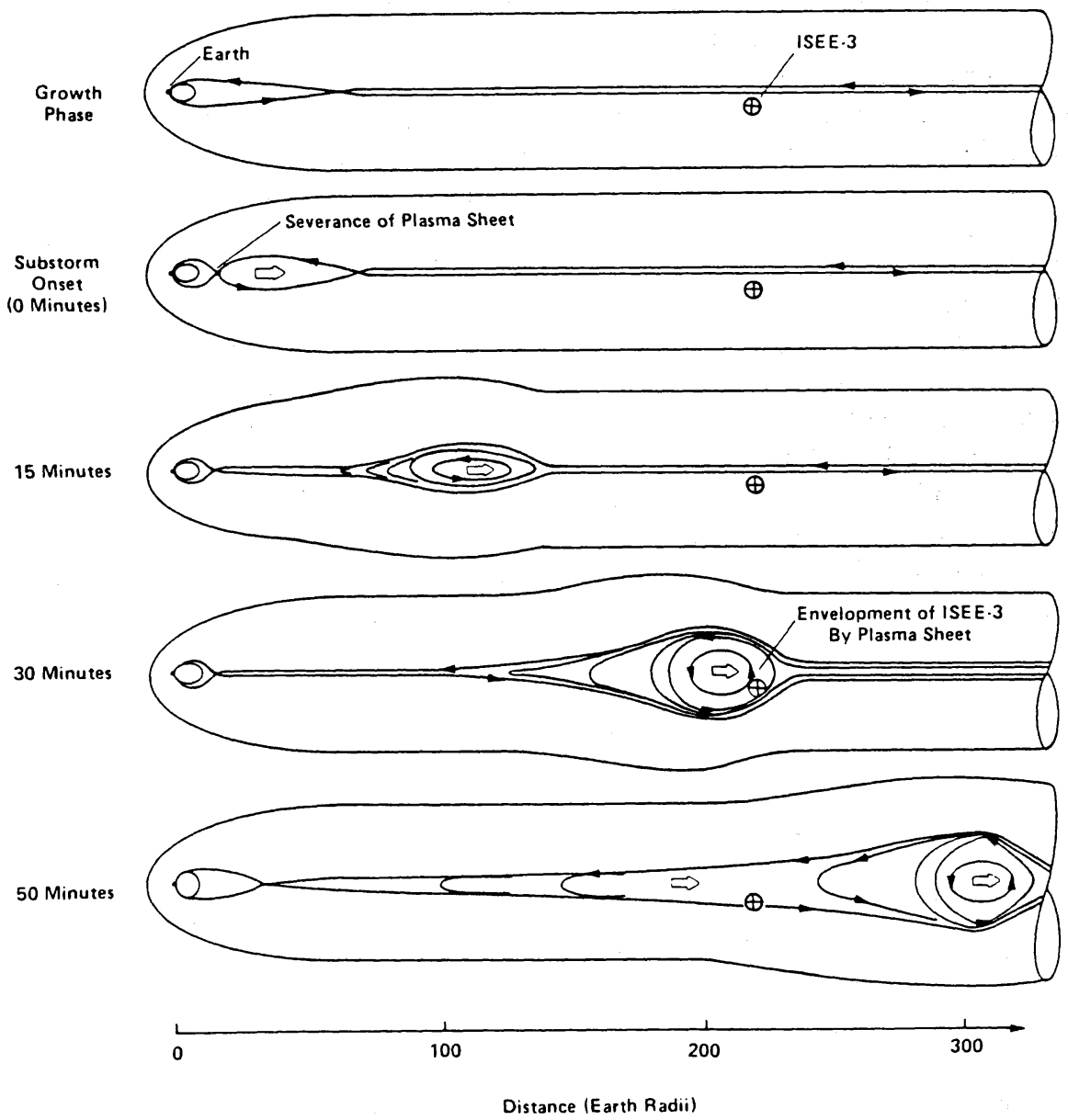

Fig. 3. Schematic diagrams showing the tailward release of a plasmoid (after HonEs et al., 1984a).

plasmoid may be more complex than envisaged in Fig. 3. Especially on the trailing end there seems to be a tendency for small-scale structures (HONES et al., 1984b; SCHOLER et al., 1985).

The typical total energy (kinetic, thermal, and magnetic) contained in a plasmoid was estimated to be of the order of $10^{15} \mathrm{~J}$ (HONES, 1985; SCHOLER et al., 1984b; SCHINDLER, 1985). If one compares this number to the energy deposition in the auroral ionospheres by Joule and particle heating during a substorm (about $10^{9} \mathrm{~W}$ per nT in $A E$; cf., AHN et al., 1983; and BAUMJOHANN and KAMIDE, 1984), one needs a one-hour substorm of about $600 \mathrm{nT}$ peak amplitude in $A E$ to get about the same value. Since a duration of one hour and a peak $A E$ of $600 \mathrm{nT}$ are rather average values 
for a typical substorm and since, furthermore, the average energy deposited in the ring current during the course of a substorm is of the same order of magnitude as the ionospheric heating (BAUMJOHANN and KAMIDE, 1984) one may say that the substorm energy is roughly equipartitioned between the three different deposition regions, i.e. auroral ionosphere, ring current, and downtail solar wind.

Clear plasmoid signatures are also observed around $100 \mathrm{R}_{\mathrm{E}}$ downtail by ISEE-3 (BAKER et al., 1984b; SCHOLER et al., 1985). They were observed at about 15-20 $\mathrm{R}_{\mathrm{E}}$ downtail by the ISEE-1/ 2 satellite pair, too (e.g., NISHIDA et al., 1983; CATTELL and MOZER, 1984; PASCHMANN et al., 1985). But as can be seen in Fig. 4, the situation is much more complex than in the distant tail. Firstly, the plasmoid has to be localized in local time. This is not unlikely, since also the substorm current wedge (thought to be connected to the plasmoid's near-earth X-type neutral line; cf. simulation results by SATO et al., 1983, 1984) is of localized nature (e.g., BAUMJOHANN and OPGENOORTH, 1984). Secondly, the plasmoid has to make a duskward "detour" to account for the interval of weak tailward plasma flow between the episodes of strong tailward and strong earthward flows. PASCHMANN et al. (1985) - and the present author-leave it to the reader how he/she judges this needed duskward detour.

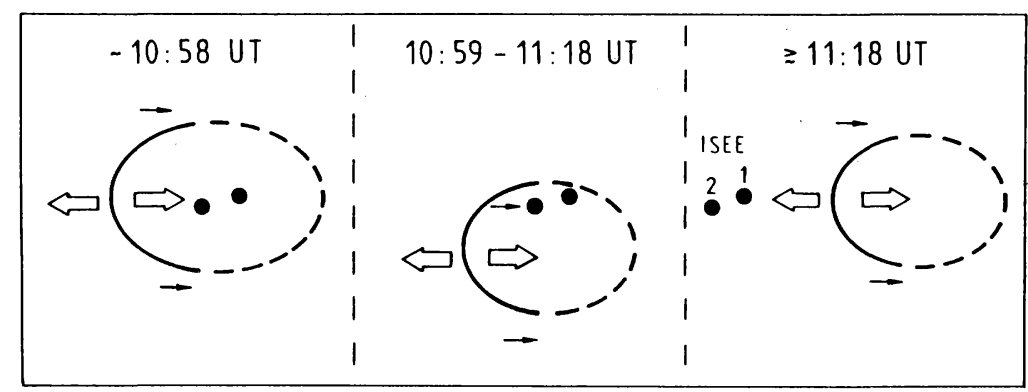

Fig. 4. Postulated relative configuration of neutral line (solid/dashed curve) and ISEE-1/2 in the neutral sheet ( $x-y$ plane) for (a) high-speed tailward flow about 3 min after substorm onset, (b) period of weak tailward flows, which precedes (c) the onset of strong earthward flows (from PASCHMANN et al., 1985).

It is, however, not unlikely that the presence of ongoing reconnection at the active near-earth X-line provides for more complexity then shown in the typically drawn simplified plasmoid picture-see, for example, the microstructure found by BIEBER et al. (1984). Moreover, it may well be that a satellite pair in the deep tail (and the resulting lowering of the number of degrees of freedom to draw satellite trajectories through the plasmoid) would find even more evidence than aforementioned of small-scale internal structure within the large-scale deep-tail plasmoid.

Finally, the author should not miss to mention that the above described complexity (and possible ambiguity) of the near-tail observation has led a few scientists to express great discomfort with the near-earth reconnection/plasmoid 
model. A lively description of this topic (and subsequent discussion with the audience) can be found in ROSTOKER (1985) and will not be rehearsed here. But the author would like to express his personal opinion that even if the present model of near-tail reconnection is still far from the "final wisdom" stage, any alternative explanations do not seem to be far behind the stage of "cartoon physics" yet.

\section{Substorm Onset Triggering}

One of the most important question of substorm dynamics is the question for the mechanism of substorm onset triggering, i.e. what causes the onset of the sudden explosive release of previously stored magnetotail energy during the expansive phase. During the last two years considerable progress has been made observationally as well as by numerical simulation. Furthermore, the effect of an oxygen ion admixture was observationally verified.

\subsection{Observations}

During the last two years the following substorm onset trigger mechanism were identified or further supported observationally:

(i) Triggering by (transient) northward turnings of the IMF (ROSTOKER et al., 1983; ROSTOKER, 1983).

(ii) Triggering by suddenly enhanced solar wind pressure in $\mathrm{SI}^{+}$(IYEMORI and TSUNOMURA, 1983).

(iii) Triggering by purely internal processes (HORWITZ, 1985).

Figure 5 shows an example of the first-mentioned trigger mechanism. Shortly after the IMF has turned southward around 0715 UT the ground-based magnetometers show some dissipation of substorm energy by the driven convectional electrojets. About one hour later the IMF turns rapidly northward reaching small positive values of $B_{z}$ and at exactly the same time the magnetic data signifies the onset of a strong expansion phase. This is a remarkably clear example of the northward turning trigger. Other examples show that substorm expansive phase onsets are also triggered by transient northward turnings and even by northward turnings where $\partial B_{z} / \partial t$ is positive but $B_{z}$ remains negative.

Figure 6 summarizes a statistical study of the time lag between sudden impulses with increased $\left(\mathrm{SI}^{+}\right)$or decreased $\left(\mathrm{SI}^{-}\right)$solar wind pressure behind the shock front and the onset of clear Pi2 pulsations, which are caused by the sudden switch-on of the current wedge during substorm onset (cf., BAUMJOHANN and GLABMEIER, 1984). Not all $\mathrm{SI}^{+}$trigger substorm onset (probably this depends on the availability of stored magnetotail energy) but the majority does and there is a clear tendency for substorm expansive phases to occur about $10 \mathrm{~min}$ after the $\mathrm{SI}^{+}$. Sudden decreases of solar wind pressure statistically do not trigger substorms and the apparent negative time delay may be caused by the preference of $\mathrm{SI}^{-}$to occur in $\mathrm{SI}^{+} \mathrm{SI}^{-}$pairs.

Finally, Figure 7 shows an example of a most probably purely internal onset triggering: while the transverse IMF components remain rather steady for an extended interval, the $A L$ index suddenly drops to about $-500 \mathrm{nT}$ thus indicating the 

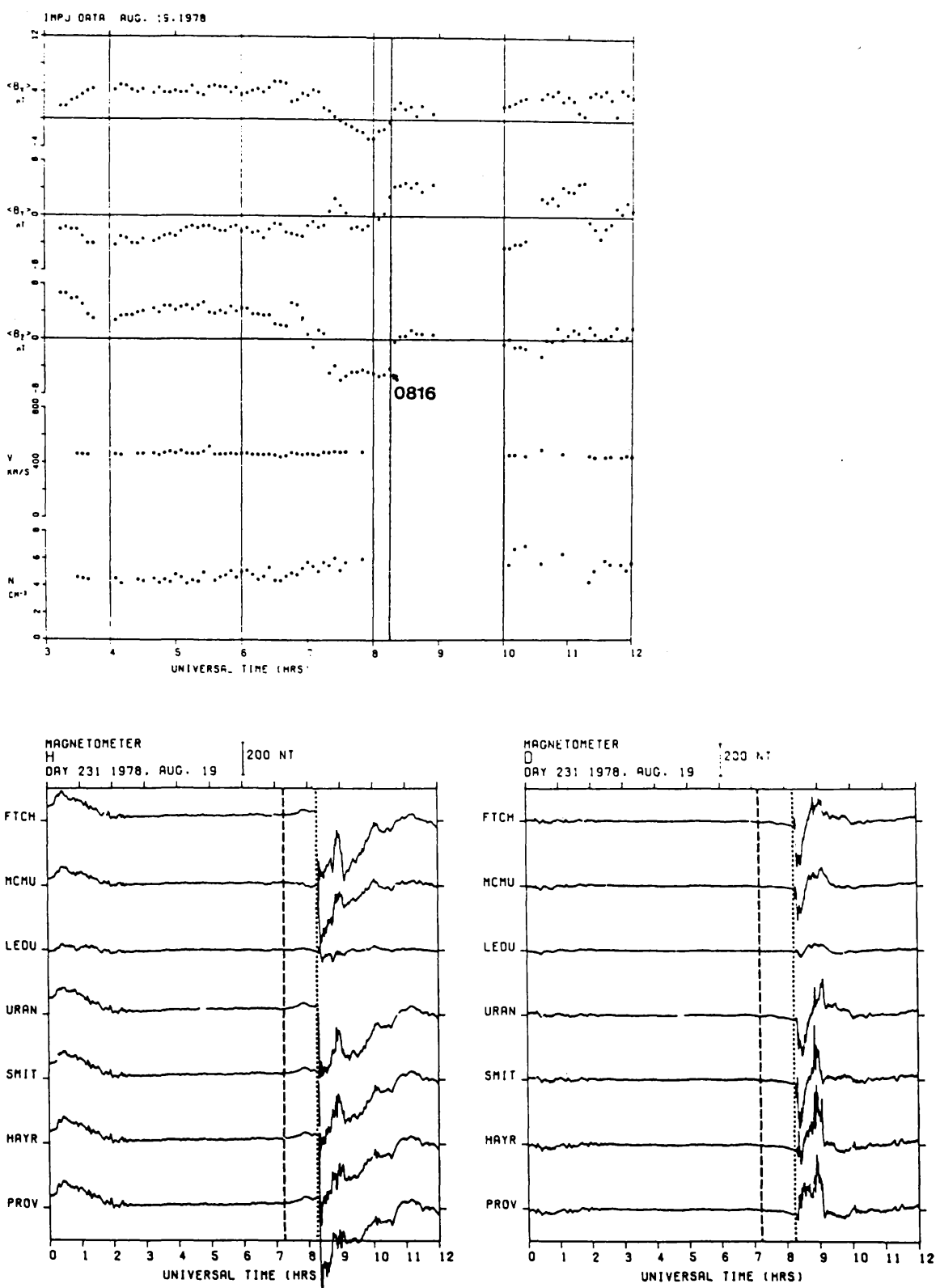

Fig. 5. Interplanetary magnetic field components, solar wind bulk velocity and density (all upper diagram) and $H$ and $D$ components measured by ground-based magnetometers around a substorm onset at 0816 UT (from RoSTOKER, 1983). 

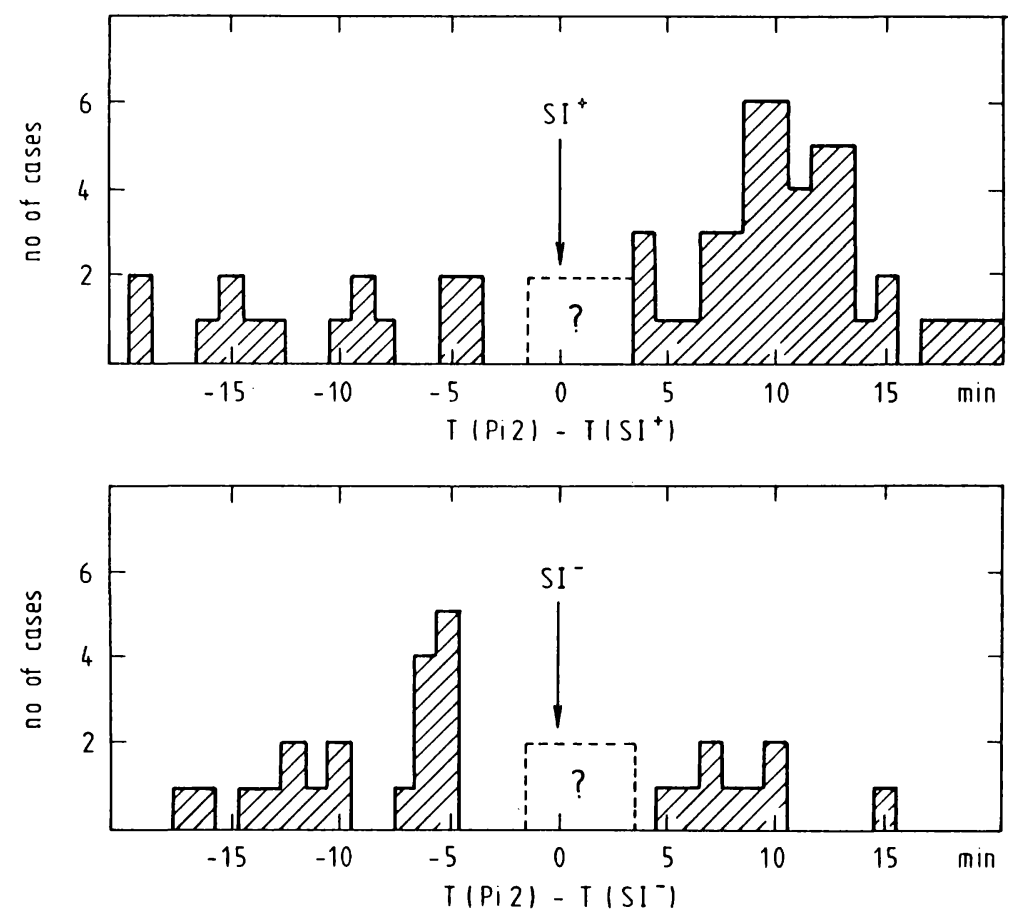

Fig. 6. Distribution of the time lag between substorm onset (defined as onset of Pi2 pulsations) and $\mathrm{SI}^{+}$ (sudden impulses associated with solar wind pressure increases; upper panel) and $\mathrm{SI}^{-}$(SI associated with s.w. pressure decrease; lower panel). No data was analyzed in the question-marked boxes around the SI in order not to confuse Pi2 and SI. (Adapted from IYemORI and TsunOMURA, 1983.)

onset of a substorm expansion phase. HoRwITZ (1985) did not look for solar wind pressure variations, but these occur far less often than and are, moreover, mostly accompanied by IMF variations. Thus, there is good reason to believe that at least the majority of his cases are caused by purely internal triggering.

In summary, we have good observational evidence nowadays that the aforementioned three triggering mechanisms, which were already proposed much earlier, do actually operate at times. But there is no statistical study yet, which gives the relative percentage of occurrence. Such a study could easily be done by checking IMF and solar wind pressure data for all sudden drops in $A L$ or sudden onsets of $\mathrm{Pi} 2$ pulsations within a given time interval. The author hopes that such a study is done soon and would like to report on the results in his Reporter Talk in 1987.

\subsection{Theory and simulation}

The most likely instability which leads to the onset of tail reconnection, formation of the near-earth X-line and plasmoid formation, i.e. to substorm onset, is 
10 September 1979
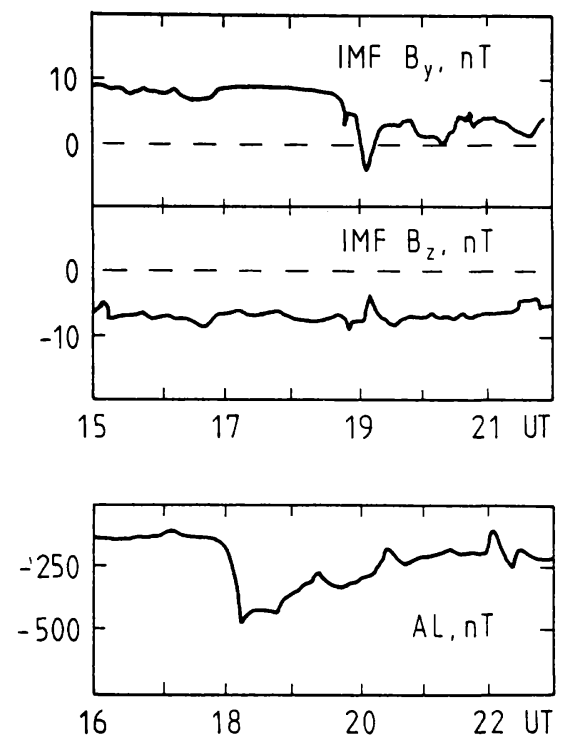

Fig. 7. IMF $B_{y}$ and $B_{z}$ component variations as measured by ISEE-1 (upper diagram) and $A L$ index (lower diagram). The lower panel is shifted by one hour to later times to allow for the transit-time delay of solar wind structures between ISEE-3 and the earth's magnetosphere (from HoRwITZ, 1985).

the ion tearing mode. The actual growth rate of the ion tearing mode depends on many parameters, but a simplified version for a long-wavelength limit is given by

$$
\gamma \sim v_{\mathrm{i}} \sqrt{\rho_{\mathrm{i}}^{3} / L_{z}^{5}}
$$

where $v_{\mathrm{i}}$ is the ion thermal velocity, $\rho_{\mathrm{i}}$ the ion gyroradius and $L_{z}$ the plasma sheet half-thickness. Physically speaking, the tearing mode goes unstable if the ions cannot preserve their magnetic moment when crossing the neutral sheet, i.e. if they become non-gyroscopic (see also upper panel of Fig. 10). Accordingly, the tearing mode growth rate can be increased by either heating the ions (thus increasing $v_{\mathrm{i}}$ and $\rho_{\mathrm{i}}$ ) or decreasing the plasma sheet half-thickness. Typically, the latter is thought of as leading to the explosive onset of the ion tearing mode.

In a recent computer simulation BIRN and SCHINDLER (1985) have shown the effect of applying a duskward interplanetary electric field along the magnetotail on its internal structure. Their first simulation run pertains to the observations of HORWITZ (1985), i.e. constant southward IMF, and thus a uniform duskward IEF along the magnetotail. As can be seen in Fig. 8 this IEF transports magnetic field lines to the neutral sheet and decreases the plasma sheet half-thickness. Hence, if this process operates long enough, it may well decrease $L_{z}$ below the limit needed to permit 

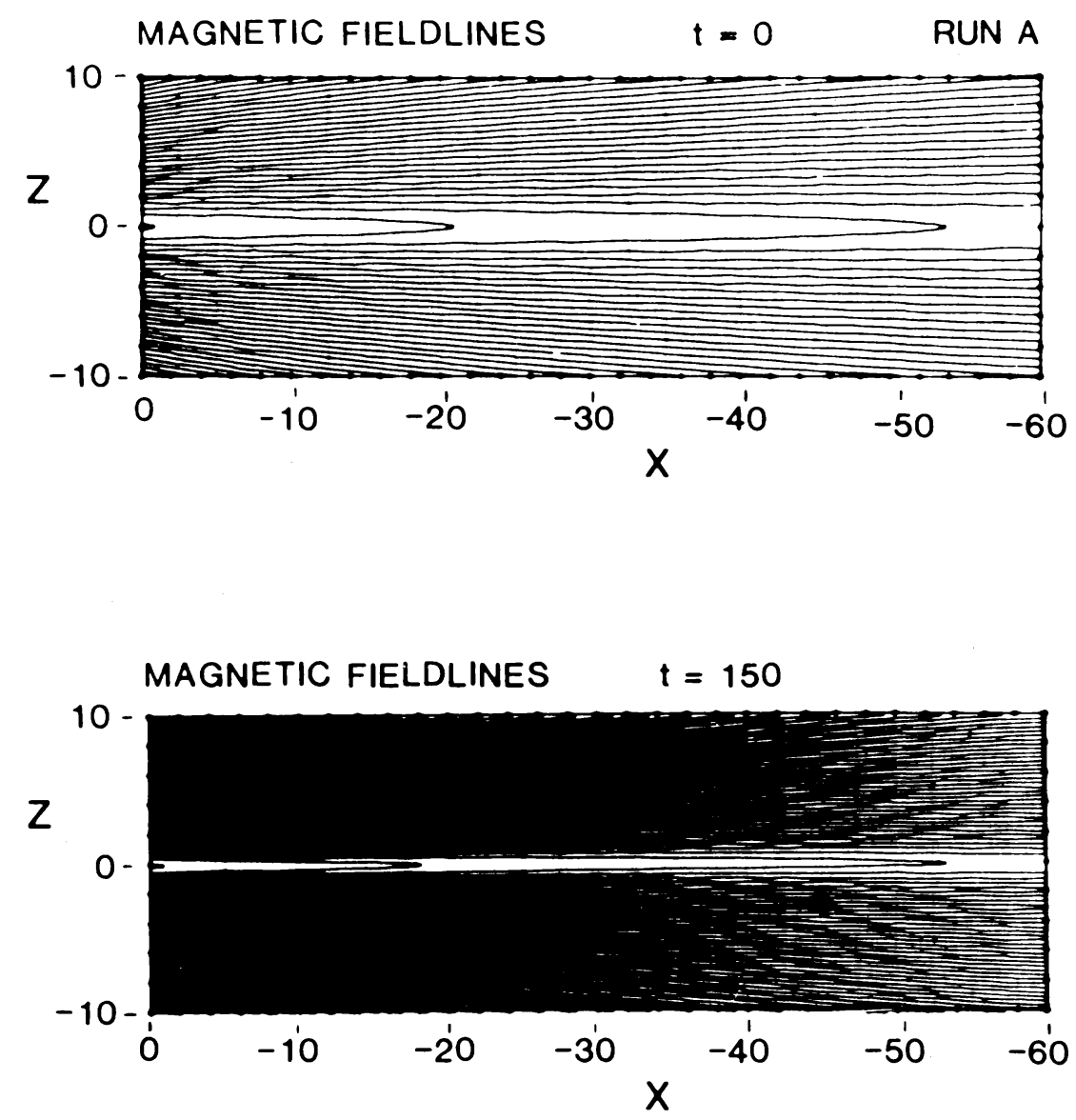

Fig. 8. Magnetic field lines in the meridional $x-z$ plane at the start of a simulation run (upper panel) and 150 time steps later (lower panel). (From BIRN and SCHINDLER, 1985.)

development of the ion tearing mode. This may explain the internal triggering mechanism.

It may also happen that the IMF turns towards north before this limit is reached, but even then there is a good chance for substorm triggering. Birn and Schindler simulated the effects of an inhomogeneous duskward IEF in another computer run and found (Fig. 9) that this will be even more effective in reducing the plasma sheet half-thickness. Since the electric field configuration in this run is similar to that after a northward turning of the IMF one may conclude that duskward IEF or southward $B_{z}$ lead to thinning of the plasma sheet, and thus favorable conditions for ion tearing, and that substorms will eventually be triggered internally if no decreased IEF due to 


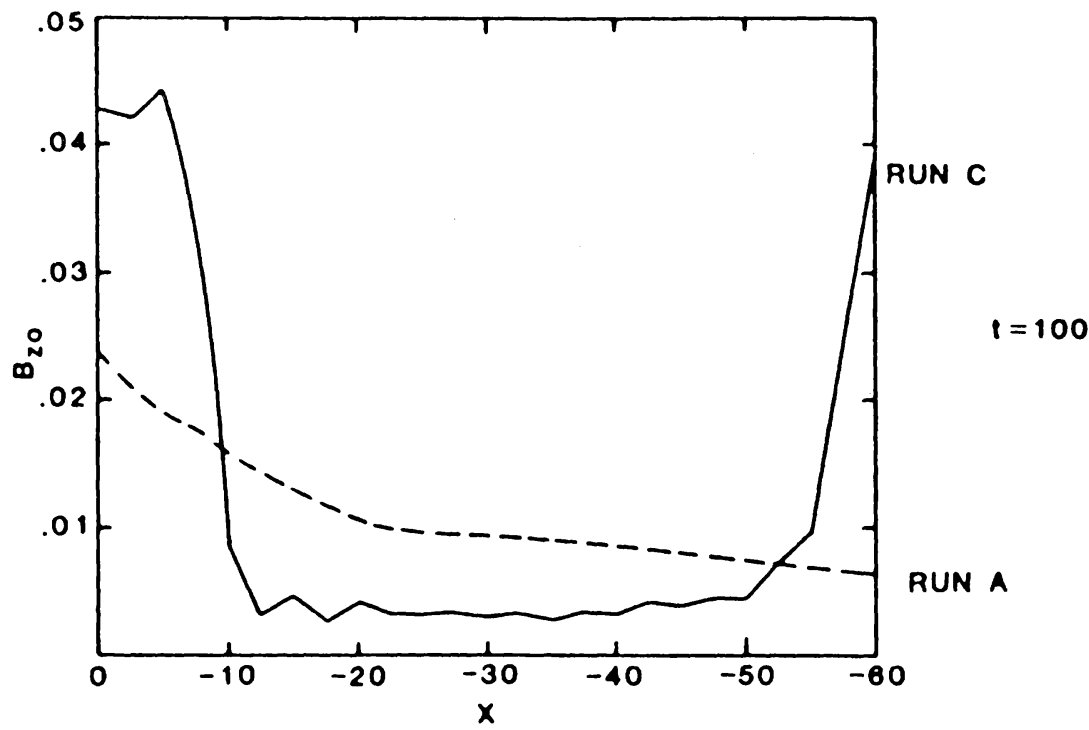

Fig. 9. Variations of the normal magnetic field component $B_{z o}$ in the neutral sheet (proportional to "plasma sheet half-thickness") along the tail at the same time step for two different simulation runs. For run A the externally applied duskward electric field was uniform along $x$ while in run $\mathrm{C}$ the electric field had a maximum around $x=-30$ with $E_{\max }(C)=E(A)$. (From BIRN and SCHINDLER, 1985.)

northward turnings of the IMF leads to stronger thinning and external triggering beforehand.

The result of stronger thinning for non-uniform IEF may also help to explain the IYEMORI and TSUNOMURA (1983) observations. BIRN and SCHINDLER (1983) showed that uniform pressure applied to the tail does not lead to tail instability, but it may be that a non-uniform pressure distribution resulting from the traversal of the shock front along the magnetotail leads to local thinning of the plasma sheet. The 10 -min time lag could then be explained consistently with the transit time of the shock front between frontside magnetopause and near-earth tail.

\subsection{Effect of $\mathrm{O}^{+}$admixture}

Some three years ago BAKER et al. (1982) have shown that an admixture of oxygen ions of ionospheric origin to the normal proton plasma sheet population will lower the tearing mode threshold, since $\mathrm{O}^{+}$has a larger gyroradius due to its larger mass and should become non-gyroscopic earlier in the sharply curved magnetic field inside the neutral sheet (cf., upper diagram of Fig. 10). The same result was reached in calculations done by ROTHWELL and YATES (1984). BAKER et al. (1982) also argued that $\mathrm{O}^{+}$mixture should lead to substorm onsets being initialized preferentially in the dusk sector of the magnetotail, since here the number density of $\mathrm{O}^{+}$is highest 

o. ELECTRON
b. PROTON
c. OXYGEN
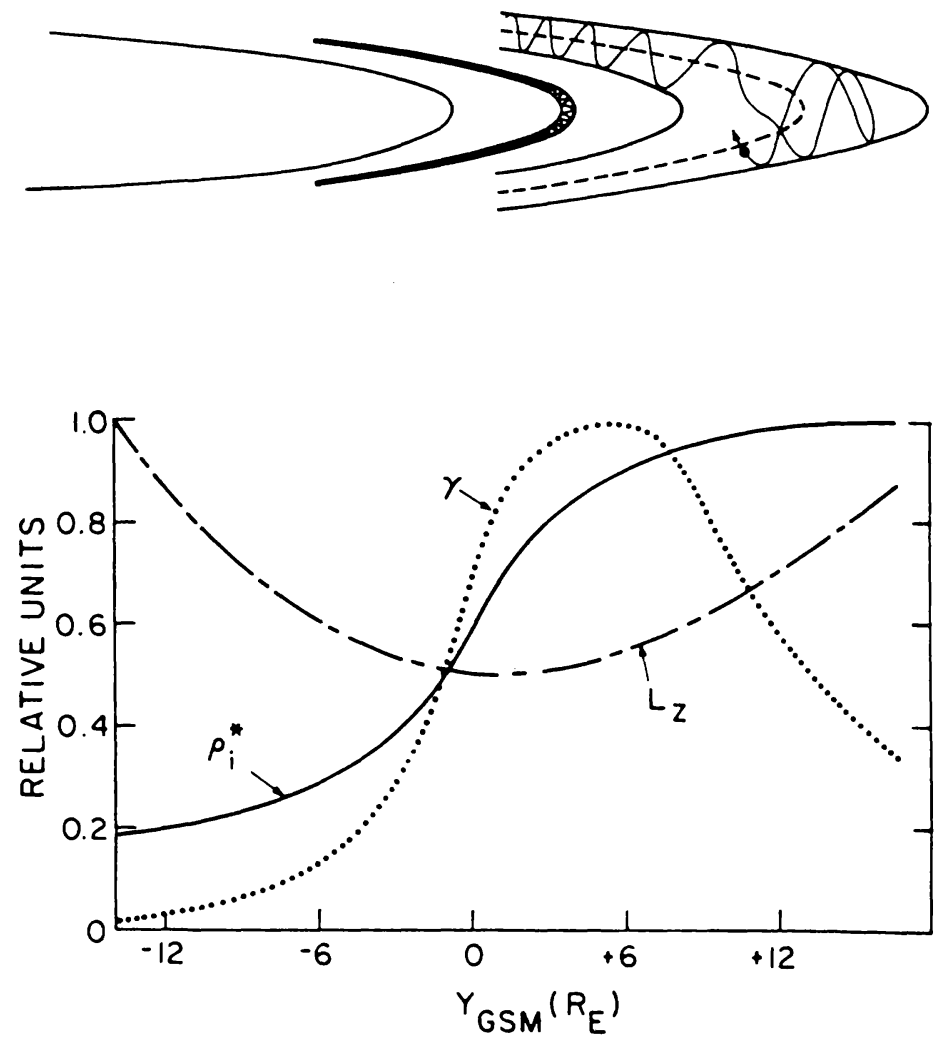

Fig. 10. Upper diagram: schematic of thermal electron and ion motion in the vicinity of a quasi-neutral sheet showing that electrons are gyroscopic while especially oxygen ions may become non-gyroscopic for realistic field line curvature. Lower diagram: dawn-dusk variation of mean ion gyroradius $\rho_{\mathrm{i}}$ (protons and oxygen) plasma sheet half-thickness $L_{z}$ and resulting tearing mode growth-rate $\gamma$. (Both diagrams from BAKER et al., 1982.)

statistically and thus the mean (density-weighted) gyroradius of protons and oxygen should be largest (lower diagram of Fig. 10).

The first observational evidence of this local time dependence of tearing mode onset from the $\mathrm{O}^{+} / \mathrm{H}^{+}$ratio was given by BAKER et al. (1985b). They compared the relative location of the substorm current wedge during two substorms, one with a low $\mathrm{O}^{+} / \mathrm{H}^{+}$ratio (less than 0.1 at $1054 \mathrm{UT}$ ) and a later one where strong ionospheric heating had led to oxygen escape and resulted in about equal number densities of $\mathrm{O}^{+}$ and $\mathrm{H}^{+}$(at $1436 \mathrm{UT}$ ). Figure 11 shows the differential ionospheric currents built up during the two expansion phases and it can be seen that for the 1054 onset the central 
22 March 1979

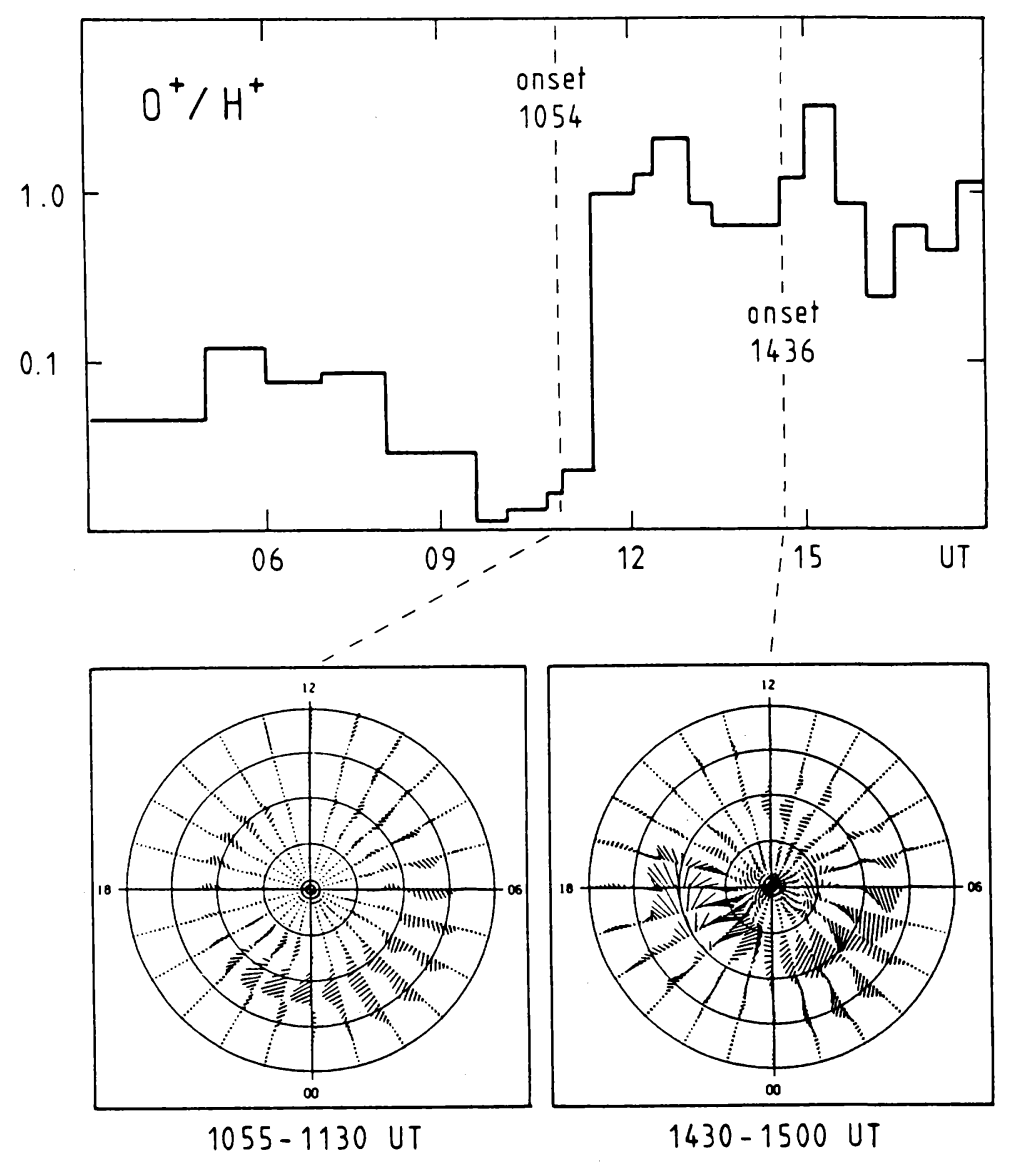

Fig. 11. $\mathrm{O}^{+} / \mathrm{H}^{+}$ratio as measured by ISEE-1 and ionospheric currents in the northern hemisphere developing after the two substorm onsets indicated by dashed lines (adapted from BAKER et al., 1985b; and Clauer and KAMIDE, 1985).

meridian of the current wedge is located in the postmidnight sector while after 1436 the wedge is centered close to local dusk (the westward electrojet between dawn and midnight belongs most probably to the driven DP2 system).

Therefore, BAKER et al. (1985) could show that an $\mathrm{O}^{+}$admixture effects substorm onset. This is especially important for multiple onset substorms where it may explain that subsequent onsets occur more and more westerly: the strong ionospheric heating due to the previous substorm supports the escape of ionospheric oxgen-as in the BAKER et al. (1985) case-and this will both lower the instability threshold and shift the onset region further westward. It may well be that ionospheric heating due to 
strong driven DP2 currents also supports $\mathrm{O}^{+}$escape into the magnetosphere and this could lead to another internal trigger mechanism, or at least a superposition of this and the ones mentioned in Subsection 4.1, even for the first substorm of a series.

\section{Substorm Recovery and Poleward Leap}

As can be seen in the preceding section quite some attention has focussed on the onset of substorms. Much less work, and not only during the last two years, was done on the other end, i.e. on the recovery phase and poleward leap. While we have a fair idea of what causes a substorm expansion phase, we still do not know what stops it.

One open question is why often not all stored magnetotail energy is exhausted in one big expansion phase but more in a series of small expansion phases, each lasting 5-10 min and sometimes called microsubstorms or substorm intensifications in a multiple onset substorm. A possible answer may be given by comparing the typical lifetime of a microsubstorm to some recent estimates on how long it takes to reconnect the old plasma sheet at the near-earth neutral line. SCHOLER et al. (1985), PASCHMANN et al. (1985) and HONES et al. (1985a) gave estimates for this duration. The estimates are based on different data sets from different satellites at different locations and for different substorms but are fairly consistently of the order of $5 \mathrm{~min}$. Thus one might argue that a microsubstorm lasts as long as it takes to reconnect the old plasma sheet in its typically not too widely extended local time sector. Then the release of tail energy proceeds in a neighbouring local time sector (often but not always to the west of the previous one) with a new microsubstorm or substorm intensification. However, this idea is still only tentative and detailed comparisons between high-resolution ground-based and satellite data are needed to confirm (or reject) it.

The second open question relates to the real end of the substorm, the substorm recovery phase and especially the poleward leap. The poleward leap is somewhat the last action of the magnetosphere to get back to pre-substorm conditions: typically one hour after expansion phase onset the aurora as well as the auroral electrojets, having reached their peak development, suddenly jump to very high latitudes (Fig. 12; HONES, 1985; HONES et al., 1985b). The poleward leap is associated with a thickening of the plasma sheet and thought to signify the tailward retreat of the near-earth neutral line (HONES et al., 1985b). At present it is unclear if this poleward leap occurs in each substorm (probably not; see e.g., example of small auroral substorm without apparent poleward leap of CRAVEN and FRANK (1985)) or only ends major expansion phases. The even more important question is what keeps the near-earth neutral line in place for something like an hour, first reconnecting the old plasma sheet and afterwards lobe field lines, and then very suddenly lets it go off tailward (to replace the old distant neutral line?): Hopefully, some answer to these questions can be given in the not too distant future by careful intercomparisons between ground-based, nearearth (ISEE-1/2) and deep-tail (ISEE-3) data. 


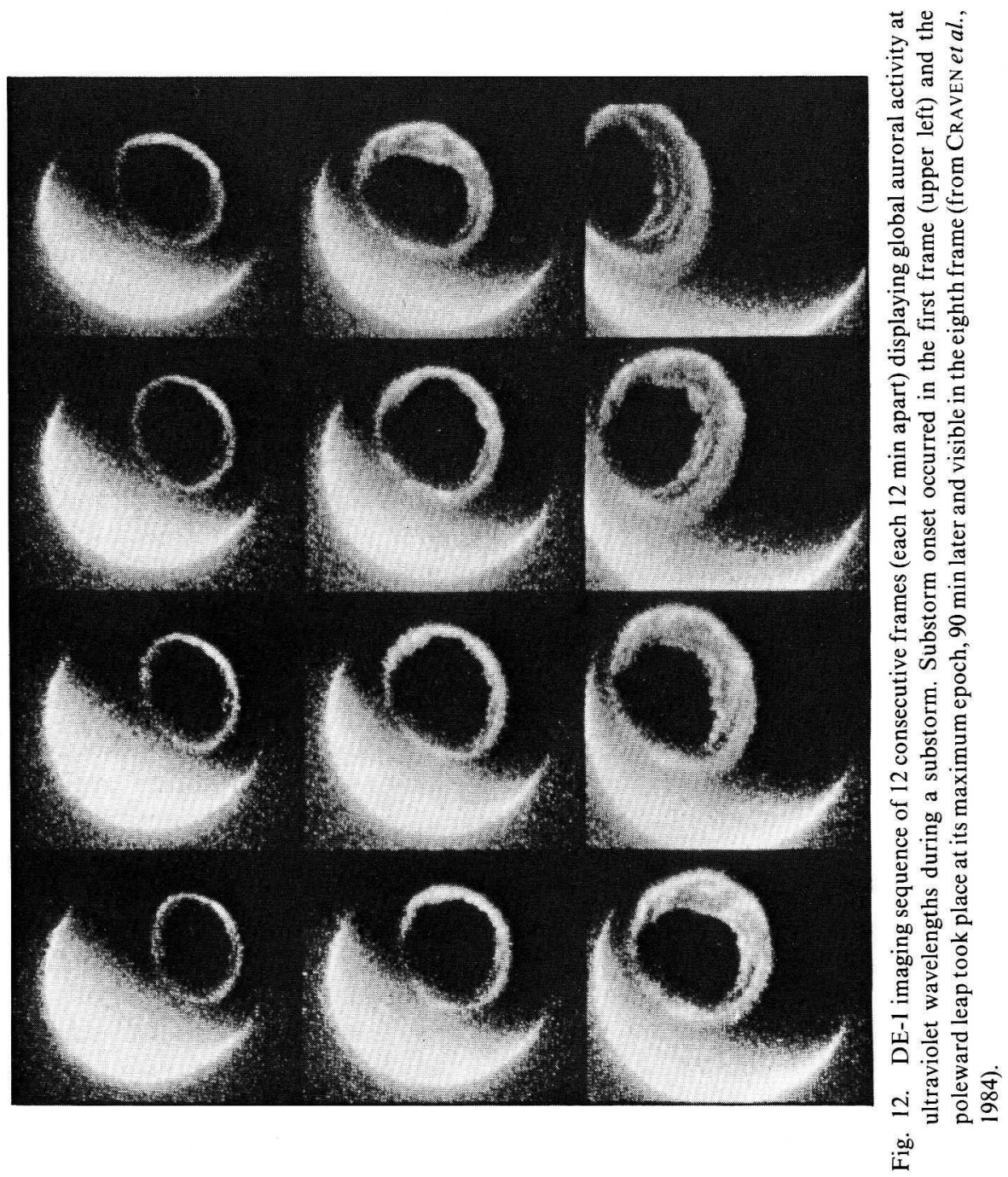


The author acknowledges financial support from the Deutsche Forschungsgemeinschaft through a Heisenberg fellowship and thanks Y. Kamide and M. Blanc for their interest to see a written version of his Reporter talk. He has profited from discussions with M. Scholer and G. Paschmann during the preparation of talk and manuscript.

\section{REFERENCES}

Ahn, B.-H., S.-I. AKasofu, and Y. Kamide, The Joule heat production rate and the particle energy injection rate as a function of the geomagnetic indices $A E$ and $A L, J$. Geophys. Res., 88, 6275-6287, 1983.

AKASOFU, S.-I., Solar wind disturbances and the solar wind-magnetosphere energy coupling function, Space Sci. Rev., 34, 173-183, 1983.

BAKER, D. N., E. W. Hones, Jr., D. T. Young, and J. BIRn, The possible role of ionospheric oxygen in the initiation and development of plasma sheet instabilities, Geophys. Res. Lett., 9, 1337-1340, 1982.

Baker, D. N., S.-I. Akasofu, W. Baumjohann, J. W. Bieber, D. H. Fairfield, E. W. Hones, Jr., B. Mauk, R. L. McPherron, and T. E. Moore, Substorms in the magnetosphere, in Solar Terrestrial Physics: Present and Future, edited by D. M. Butler and K. Papadopoulos, Chap. 8, NASA Ref. Publ. 1120, Washington, 1984a.

Baker, D. M., S. J. Bame, J. Birn, W. C. Feldman, J. T. Gosling, E. W. Hones, Jr., R. D. Zwickl, J. A. Slavin, E. J. Smith, B. T. Tsurutani, and D. J. Sibeck, Direct observations of passages of the distant neutral line $\left(80-40 \mathrm{R}_{\mathrm{E}}\right)$ following substorm onsets: ISEE-3, Geophys. Res. Lett., 11, 1042-1045, 1984b.

Baker, D. N., T. A. Fritz, R. L. McPherron, D. H. Fairfield, Y. Kamide, and W. Baumjohann, Magnetotail energy storage and release during the CDAW6 substorm analysis interval, J. Geophys. Res., 90, 1205-1260, 1985a.

Baker, D. N., T. A. Fritz, W. Lennartson, B. Wilken, H. W. Kroehl, and J. Birn, The role of heavy ionospheric ions in the localization of substorm disturbances on March 22, 1979: CDAW6, J. Geophys. Res., 90, 1273-1281, 1985 b.

Bargatze, L. F., D. N. Baker, R. L. McPherron, and E. W. Hones, Jr., Magnetospheric impulse response for many levels of geomagnetic activity, J. Geophys. Res., 90, 6387-6394, 1985.

Baumjohann, W., Ionospheric and field-aligned current systems in the auroral zone: A concise review, Adv. Space Res., 2(10), 55-62, 1983.

BaumjohanN, W., Merits and limitations of the use of geomagnetic indices in solar wind-magnetosphere coupling studies, in Solar Wind-Magnetosphere Coupling, edited by Y. Kamide and J. A. Slavin, in press, Terrapub/Reidel, Tokyo, 1986.

Baumjohann, W. and K.-H. Glabmeier, The transient response mechanism and Pi2 pulsations at substorm onset-Review and outlook, Planet. Space Sci., 32, 1361-1370, 1984.

Baumjohann, W. and Y. KAMIDE, Hemispherical Joule heating and the AEindices, J. Geophys. Res., 89, 383-388, 1984.

BaumjohanN, W. and H. J. Opgenoorth, Electric fields and currents associated with active aurora, in Magnetospheric Currents, edited by T. A. Potemra, pp. 77-85, A.G.U., Washington, 1984.

Bieber, J. W., E. C. Stone, E. W. Hones, Jr., D. N. BAKer, S. J. BAME, and R. P. LepPing, Microstructure of reconnection in earth's magnetotail, J. Geophys. Res., 89, 6705-6716, 1984.

BIRN, J. and K. SCHINDLER, Self-consistent theory of three-dimensional convection in the geomagnetic tail, J. Geophys. Res., 88, 6969-6980, 1983.

BIRN, J. and K. SCHINDLER, Computer modeling of magnetotail convection, J. Geophys. Res., 90, 3441 $3447,1985$.

CAtTell, C. A. and F. S. Mozer, Substorm electric fields in the earth's magnetotail, in Magnetic Reconnection in Space and Laboratory Plasmas, edited by E. W. Hones, Jr., pp. 208-217, A.G.U., Washington, 1984.

Clauer, C. R. and Y. KAMIDE, DP1 and DP2 current systems for the March 22, 1979, substorms, $J$. Geophys. Res., 90, 1342-1345, 1985. 
Craven, J. D. and L. A. Frank, The temporal evolution of a small auroral substorm as viewed from high altitudes with Dynamics Explorer 1, Geophys. Res. Lett., 12, 465-468, 1985.

Craven, J. D., Y. Kamide, L. A. Frank, S.-I. Akasofu, and M. Sugiura, Distribution of aurora and ionospheric currents observed simultaneously on a global scale, in Magnetospheric Currents, edited by T. A. Potemra, pp. 137-146, A.G.U., Washington, 1984.

Hones, E. W., Jr., Plasma flow in the near and distant geomagnetic tail, Adv. Space Res., 5(4), 375-389, 1985.

Hones, E. W., Jr., D. N. Baker, S. J. Bame, W. C. Feldman, J. T. Gosling, D. J. McComas, R. D. Zwickl, J. A. Slavin, E. J. Smith, and B. T. Tsurutani, Structure of the magnetotail at $220 \mathrm{R}_{\mathrm{E}}$ and its response to geomagnetic activity, Geophys. Res. Lett., 11, 5-7, 1984a.

Hones, E. W., Jr., J. Birn, D. N. Baker, S. J. Bame, W. C. Feldman, D. J. McComas, R. D. Zwick L, J. A. Slavin, E. J. Smith, and B. T. Tsurutani, Detailed examination of a plasmoid in the distant magnetotail with ISEE 3, Geophys. Res. Lett., 11, 1046-1049, 1984b.

Hones, E. W., Jr., T. A. Fritz, J. Birn, J. CoOney, and S. J. BAmE, Detailed observations of the plasma sheet during a substorm on April 24, 1979, submitted to J. Geophys. Res., 1985a.

Hones, E. W., Jr., T. J. Rosenberg, K. A. Anderson, G. K. PArks, and H. J. Singer, The poleward leap of the electrojet and the tailward retreat of the neutral line, submitted to J. Geophys. Res., 1985b.

HORwITZ, J. L., The substorm as an internal magnetospheric instability: Substorms and their characteristic time scales during intervals of steady interplanetary magnetic field, J. Geophys. Res., 90, 4164-4170, 1985.

IYEMORI, T. and S. Tsunomura, Characteristics of the association between an SC and a substorm onset, Mem. Natl. Inst. Polar Res., Spec. Issue, 26, 139-184, 1983.

Kamide, Y. and S.-I. AKASOFU, Notes on the auroral electrojet indices, Rev. Geophys. Space Phys., 21, $1647-1656,1983$.

KAMIDE, Y. and W. BAUMJOHANN, Estimation of electric fields and currents from IMS magnetometer data for the CDAW-6 intervals: Implications for substorm dynamics, J. Geophys. Res., 90, 1305-1317, 1985.

Nishida, A., Y. K. Tulunay, F. S. Mozer, C. A. Cattell, E. W. Hones, Jr., and J. Birn, Electric field evidence for tailward flow at substorm onset, J. Geophys. Res., 88, 9109-9113, 1983.

Paschmann, G., N. SCKOPKe, and E. W. Hones, Jr., Magnetotail plasma observations during the 1054 UT substorm on March 22, 1979 (CDAW 6), J. Geophys. Res., 90, 1217- 1229, 1985.

Pellinen, R. J., W. Baumjohann, W. J. Heik kila, V. A. Sergeev, A. G. Yahnin, G. Marklund, and A. O. MELNIKOV, Event study on pre-substorm phases and their relation to the energy coupling between solar wind and magnetosphere, Planet. Space Sci., 30, 371-388, 1982.

ROSTOKER, G., Triggering of expansive phase intensifications of magnetospheric substorms by northward turnings of the interplanetary magnetic field, J. Geophys. Res., 88, 6981-6993, 1983.

Rostoker, G., Definition of a substorm, physical processes in a substorm and sources of discomfort, in Magnetic Reconnection in Space and Laboratory Plasmas, edited by E. W. Hones, pp. 380-384, A.G.U., Washington, 1985.

Rostoker, G., W. BaUmJohann, and C. T. Russell, A case study of the response of the magnetosphere to changes in the interplanetary medium, J. Geophys., 53, 170-181, 1983.

Rostoker, G., S.-I. Akasofu, W. Baumjohann, Y. Kamide, and R. L. McPherron, The roles of direct input of energy from the solar wind and unloading of stored magnetotail energy in driving magnetospheric substorms, submitted to J. Geophys. Res., 1985.

Rothwell, P. L. and G. K. YATES, Global single ion effects within the earth's plasma sheet, in Magnetic Reconnection in Space and Laboratory Plasmas, edited by E. W. Hones, pp. 51-60, A.G.U., Washington, 1984.

Sato, T., T. Hayashi, R. J. Walker, and M. Ashour-Abdalla, Neutral sheet current interruption and field-aligned current generation by three-dimensional driven reconnection, Geophys. Res. Lett., 10, $221-224,1983$.

Sato, T., R. J. Walker, and M. Ashour-Abdalla, Driven magnetic reconnection in three dimensions: Energy conversion and field-aligned current conservation, J. Geophys. Res., 89, 9761-9769, 1984. 
SCHINDLER, K., Plasmoids in planetary magnetic fields and the solar corona, in Future Missions in Solar, Heliospheric \& Space Plasma Physics, edited by E. Rolfe and B. Battrick, pp. 101-105, ESA SP-235, 1985.

Scholer, M., G. Gloeckler, B. Klecker, F. M. Ipavich, D. Hovestadt, and E. J. Smith, Fast moving plasma structures in the distant magnetotail, J. Geophys. Res., 89, 6717-6727, 1984a.

Scholer, M., G. Gloeckler, D. Hovestadt, B. Klecker, and F. M. IPavich, Characteristics of plasmoid-like structures in the distant magnetotail, J. Geophys. Res., 89, 8872-8876, 1984b.

Scholer, M., D. N. Baker, S. J. Bame, W. Baumjohann, G. Gloeckler, F. M. IPavich, E. J. Smith, and T. TSURUtANI, Correlated observations of substorm effects in the near-earth region and the deep magnetotail, J. Geophys. Res., 90, 4021-4026, 1985.

Slavin, J. A., E. J. Smith, B. T. Tsurutani, D. G. Sibeck, H. J. Singer, D. N. Baker, J. T. Gosling, E. W. HONES, Jr., and F. L. SCARF, Substorm associated traveling compression regions in the distant tail: ISEE-3 geotail observations, Geophys. Res. Lett., 11, 657-660, 1984. 